\title{
Raskaudenkeskeytyslain vaikutuksesta rikollisten aborttien sekä abortus arteprovocatusten lukumäärään Helsingissä
}

\author{
Mikko, Olki.
}

Sitä tosiasiaa on pidettävä varsin luonnollisena, että lailliset raskaudenkeskey.tykset ovat aborttilakimme voimaantulon jälkeen huomattavasti lisääntyneet. Ennen 1. 7. 1950 oli lääkäri vakiintuneen tavan mukaan oikeutettu suorittamaan raskaudenkeskeytyksen ainoastaan mikäli raskauden jatkuminen uhkasi vakavasti naisen henkeä tai terveyttä, eli puhtaan medisiinisen indikaation pohjalla. Pitkäsen (1947) suorittaman tutkimuksen mukaan tehtiin maassamme vuosina 1935-48 noin tuhat laillista keskeytystä vuosittain. 1. 7. 50 voimaanastuneella lailla raskaudenkeskeytyksestä määrättiin tarkemmin keskeytykseen oikeuttavat indikaatiot. Varsinaisten lääketieteellisten indikaatioitten lisäksi otettiin lakiin humanitääriset, eugeeniset sekä lääketieteellis-sosiaaliset indikaatiot. Viime mainittu syntyi kompromissina puhdasta sosiaalista indikaatiota kannattavien ja sitä vastustavien piirien välillä ja se sai laissa seuraavan muodon: Raskaus voidaan naisen suostumuksella keskeyttää, kun raskauden jatkuminen tai lapsen synnyttäminen naisen sairauden, ruumiinvian tai heikkouden vuoksi aiheuttaisi hänen ruumiinsa tai sielunsa terveydelle vakavan vaaran; tätä vaaraa arvosteltaessa otettakoon huomioon myöskin naisen terveyteen vaikuttavat erikoisen vaikeat elämän olot ja muut olosuhteet.

Indikaatioalueen näin laajennuttúa ja raskaudenkeskeytyksen tultua lakimääräisenä toimenpiteenä lääkärien sekä yleisön keskuudessa entistä enemmän tunnetuksi ja yhteiskunnan hyväksymäksi toimenpiteeksi oli odotettavissa, että laillisten keskey- 
tysten lukumäärä vuosittain huomattavasti nousisi. Vuonna 1952 oli legaaliaborttien lukumäärä 3.310 , eli noin kolminkertainen lakia edeltäneeseen aikaan verrattuna. Vuoden 1953 vastaavat luvut osoittavat laillisten keskeytysten määrän jatkuvasti lisääntyvän. (1953 suoritettiin ennakkotietojen mukaan yli 3.700 keskeytystä).

Tehokkaan aborttilainsäädännön yhtenä päätarkoituksena on katsottu olevan sen kyky vaikuttaa pienentävästi kriminellien aborttien lukumäärään ja lain tehokkuutta on pyritty arvostelemaan tätä mittapuuta käyttäen (Ingelman-Sundberg 1951). Ruotsissa lisättiin vuoden 1939 aborttilakiin, jonka pääpiirteittäin voimme katsoa vastaavan omaa lakiamme, vuonna 1946 sosiaalis-lääketieteellinen indikaatio nk. förutsedd svaghet. Tällä toimenpiteellä on epäilemättä haluttu saada osa kriminelliin aborttiin turvautuvista naisista johdetuksi laillisen abortin piiriin, tai tätä tietä ainakin sosiaalisen huollon ja henkilökohtaisen valistustyön kohteeksi. Tämä, vastuunsa tuntevan lääkärikunnan kannalta varsin arveluttava ja vastustettu toimenpide, ei ole tuonut toivottua tulosta kriminellien aborttien suhteen Ruotsissa. Vastailmestyneessä Ruotsin aborttimietinnössä todetaan, että lain voimaantultua on legaalien ja illegaalien aborttien summa pysynyt samana. Mietintöä kritisoivat asiantuntijat pitävät kaikesta huolimatta todennäköisenä, että rikolliset keskeytykset ovat jatkuvasti lisääntyneet laillisten keskeytysten ohella. Suorittamassaan tutkimuksessa vuodelta 1951 on Ingelman-Sundberg tutkinut aborttilain vaikutusta Tukholman kaupungissa ja tullut silloin äskenmainittuun tulokseen.

Saadaksemme jonkinlaisen käsityksen tilanteesta meillä Suomessa, olen prof. Aarno Turusen kehoituksesta suorittanut tutkimuksen Helsingin sairaaloissa, tarkoituksena selvittää aborttilain vaikutusta aborttitilanteeseen Helsingin kaupungissa.

A in e is to. Tutkimus perustuu Helsingin sairaaloissa vuosina 1948-1952 hoidettuihin, helsinkiläisten potilaiden synnytyksiin, abortteihin, abortin jälkitiloihin, laillisiin raskaudenkeskey- 
tyksiin, kohdunulkoisiin raskauksiin sekä muihin raskaudesta aiheutuviin sairaustiloihin (mola, chorionepitelioma).

Tiedot on kerätty kaikista Helsingin sairaaloista läpikäymällä sairaaloiden synnytys- ja leikkauspäiväkirjat sekä polikliiniset kortistot. Tiedot on kerätty huolellisesti, pyrkien välttämään tapausten kertautumista. Esimerkiksi Naistenklinikan aineistossa, joka muodostaa lähes puolet koko Helsingin aineistosta, on polikliiniset diagnoosit osastolla hoidetuista potilaista tarkastettu sairaskertomuksista. Aborteiksi tai abortin jälkitiloiksi on huomioitu vain kaikki verifioidut tapaukset, jotka joko toimenpidettä suoritettaessa tai patologis-anatomisen lausunnon perusteella on varmuudella todettu. Kaikki epäselvät vuototapaukset, joiden taudin määrityksenä eșintyy abortus? (kysymysmerkillä) on jätetty huomioimatta tutkimuksessa. Näin menetellen nvat tutkimuksessa esiintyvät aborttien lukumäärät saatu pelkistettyä minimiarvoiksi.

Tutkimus on suoritettu vertaamalla vuosittaisia aborttien ja arteprovocatusten lukuja graviditeettien kokonaismäärään vuosittain. Täten on saatu vältetyksi vuosittaisista syntyväisyydenvaihteluista johtuvat virheet. Vertailun suorittamista varten on aineisto jaettu kahteen osaan, siten, että ensimmäinen osa käsittää ajan vuoden 1948 alusta kesäkuun viimeiseen päivään vuonna 1950 ja toinen osa heinäkuun 1 päivästä 1950 vuoden 1952 loppuun.

Helsinki on valittu tutkimuskohteeksi siitä syystä, että sen väestöllä voidaan olettaa olevan paras mahdollinen tieto syntyvyydensäännöstelykeinoista. Samoin voidaan pitää todennäköisenä, että aborttilaki ja sen suomat mahdollisuudet ovat helsinkiläisille sekä teoriassa tutuimmat ja myös käytännössä parhaiten hyväksi käytettävissä. Helsinkiläisväestö ei tosin syntyväisyytensä enempää kuin abortti- ja arteprovocatus-lukujensa puolesta edusta koko maan keskitasoa. Edellämainituista syistä pitäisi aborttilain ja yleisen rikollisiin raskaudenkeskeytyksiin kohdistuneen valistustyön vaikutusten kuitenkin ensimmäiseksi ja kaikkein selvimpänä tulla näkyviin helsinkiläisten keskuudessa.

Tulokset (taulukko 1). 
T a $\iota$ ukko 1 .

Aborttien sekä abortus arteprovocatusten suhde raskaudentilojen määrään helsinkiläisillä potilailla vuosina 1948-1952.

\begin{tabular}{|c|c|c|c|c|c|c|c|c|}
\hline & $1948 \quad 1949$ & 1950 & $\begin{array}{c}\text { Yh- } \\
\text { teensä }\end{array}$ & 1950 & 1951 & 1952 & $\begin{array}{c}\text { Yh- } \\
\text { teensää }\end{array}$ & $\begin{array}{l}\text { Kaik- } \\
\text { kiaan }\end{array}$ \\
\hline Synnytykset ...... & $\begin{array}{r}7,4036,713 \\
77,5 \quad 73,2\end{array}$ & $\begin{array}{r}3,019 \\
72,8\end{array}$ & $\begin{array}{r}17,135 \\
75,3\end{array}$ & $\begin{array}{r}3,058 \\
71,6\end{array}$ & $\begin{array}{r}6,263 \\
71,5\end{array}$ & $\begin{array}{r}6,092 \\
69,5\end{array}$ & $\begin{array}{r}15,413 \\
70,5\end{array}$ & $\begin{array}{r}32,548 \\
73,3\end{array}$ \\
\hline Abortit ja jälkitilat & $\begin{array}{rr}1,747 & 1,824 \\
18,3 & 20,9\end{array}$ & $\begin{array}{r}881 \\
21,2\end{array}$ & $\begin{array}{r}4,452 \\
19,5\end{array}$ & $\begin{array}{r}882 \\
20,6\end{array}$ & $\begin{array}{r}1,884 \\
21,5\end{array}$ & $\begin{array}{r}1,875 \\
21,3\end{array}$ & $\begin{array}{r}4,641 \\
21,2\end{array}$ & $\begin{array}{r}9,093 \\
20,3\end{array}$ \\
\hline $\begin{array}{c}\text { Abortus arteprovo- } \\
\text { catukset } \ldots \ldots \ldots\end{array}$ & $\begin{array}{rr}269 & 390 \\
2,8 & 4,3\end{array}$ & $\begin{array}{r}191 \\
4,6\end{array}$ & $\begin{array}{r}850 \\
3,7\end{array}$ & $\begin{array}{r}257 \\
6,0\end{array}$ & $\begin{array}{r}489 \\
5,6\end{array}$ & $\begin{array}{r}710 \\
7,9\end{array}$ & $\begin{array}{r}1,456 \\
6,9\end{array}$ & $\begin{array}{r}2,306 \\
5,2\end{array}$ \\
\hline $\begin{array}{c}\text { Extrauterinat ja } \\
\text { molat } \ldots \ldots \ldots \ldots\end{array}$ & $\begin{array}{rr}135 & 148 \\
1,4 & 1,6 \\
\end{array}$ & $\begin{array}{r}57 \\
1,4 \\
\end{array}$ & $\begin{array}{r}340 \\
1,5\end{array}$ & $\begin{array}{r}80 \\
1,8 \\
\end{array}$ & $\begin{array}{r}119 \\
1,4 \\
\end{array}$ & $\begin{array}{l}116 \\
1,3 \\
\end{array}$ & $\begin{array}{r}315 \\
1,4\end{array}$ & $\begin{array}{r}655 \\
1,2 \\
\end{array}$ \\
\hline Kaikkiaan & $9,5549,075$ & 4,148 & 22,777 & 4,277 & 8,755 & 8,796 & 21,825 & 44,602 \\
\hline
\end{tabular}

Ta $u l u k k \circ 2$.

Lahden kaupungin naistensairaala.

\begin{tabular}{|c|c|c|c|c|c|c|c|c|c|}
\hline & 1948 & 1949 & 1950 & $\begin{array}{c}\text { Yh- } \\
\text { teensä }\end{array}$ & 1950 & 1951 & 1952 & $\begin{array}{c}\text { Yh- } \\
\text { teensă }\end{array}$ & $\begin{array}{l}\text { Kaik- } \\
\text { kiaan }\end{array}$ \\
\hline Synnytykset & $\begin{array}{r}1,192 \\
85,9\end{array}$ & $\begin{array}{l}1,047 \\
80,4\end{array}$ & $\begin{array}{r}521 \\
81,2\end{array}$ & $\begin{array}{r}2,760 \\
82,9\end{array}$ & $\begin{array}{r}484 \\
80,9\end{array}$ & $\begin{array}{r}983 \\
77,1\end{array}$ & $\begin{array}{r}1,009 \\
78,7\end{array}$ & $\begin{array}{r}2,476 \\
78,4\end{array}$ & $\begin{array}{r}5,236 \\
80,7\end{array}$ \\
\hline Abortit ja jälkitilat & $\begin{array}{r}173 \\
12,5\end{array}$ & $\begin{array}{r}208 \\
15,9\end{array}$ & $\begin{array}{r}102 \\
15,9\end{array}$ & $\begin{array}{l}483 \\
14,5\end{array}$ & $\begin{array}{r}88 \\
14,6\end{array}$ & $\begin{array}{r}217 \\
17,0\end{array}$ & $\begin{array}{r}190 \\
14,8\end{array}$ & $\begin{array}{r}495 \\
15,7\end{array}$ & $\begin{array}{r}978 \\
15,0\end{array}$ \\
\hline $\begin{array}{c}\text { Abortus arteprovo- } \\
\text { catukset } \ldots \ldots \ldots \ldots\end{array}$ & $\begin{array}{r}15 \\
1,1\end{array}$ & $\begin{array}{r}36 \\
2,7\end{array}$ & $\begin{array}{r}15 \\
2,3\end{array}$ & $\begin{array}{r}66 \\
1,9\end{array}$ & $\begin{array}{r}24 \\
3,9\end{array}$ & $\begin{array}{r}54 \\
4,3\end{array}$ & $\begin{array}{r}69 \\
5,4\end{array}$ & $\begin{array}{r}147 \\
4,6\end{array}$ & $\begin{array}{l}213 \\
3,3\end{array}$ \\
\hline $\begin{array}{c}\text { Extrauterinat ja } \\
\text { molat } \quad \ldots \ldots \ldots . .\end{array}$ & $\begin{array}{r}6 \\
0,5 \\
\end{array}$ & $\begin{array}{r}13 \\
1,0\end{array}$ & $\begin{array}{r}4 \\
0,6 \\
\end{array}$ & $\begin{array}{l}23 \\
0,7\end{array}$ & $\begin{array}{r}5 \\
0,6\end{array}$ & $\begin{array}{r}21 \\
1,6\end{array}$ & $\begin{array}{l}14 \\
1,1\end{array}$ & $\begin{array}{r}40 \\
1,3\end{array}$ & $\begin{array}{r}63 \\
1,0 \\
\end{array}$ \\
\hline Kaikkiaan & 1,386 & 1,304 & 642 & 3,332 & 601 & 1,275 & 1,282 & 3,158 & 6,490 \\
\hline
\end{tabular}

Verrattaessa aikaa ( $2 \frac{1 / 2}{2}$ v.) ennen raskaudenkeskeytyslain voimaanastumista, yhtä pitkään ajanjaksoon lain voimaanastumisen jälkeen, huomataan, että raskauksien kokonaismäärä on myöhäisempänä aikakautena vähentynyt vain 952:1la, mutta synny- 
tyksien määrä on samana aikana vähentynyt $1722: 11 a$. Tämä osoittaa, että aborttilain aikana on aborttien ja abortus arteprovocatusten yhteismäärä lisääntynyt 795 tapauksella, joista aborttien osalle tulee 189 ja laillisten raskaudenkeskeytysten osalle 606 . Laillisten raskaudenkeskeytysten suuren lisääntymisen $(71.3 \%$ ) ohella on myöskin aborttien kohdalla tapahtunut lisääntymistä, vaikkakin huomattavasti pienemmässä määrässä $(4.2 \%)$. Aborttilain vaikutus ei siis meilläkään, ainakaan tämän lyhyen observation kuluessa, ilmene rikollisten raskaudenkeskeytysten lukumäärän vähenemisenä. Aborttien suhteellinen osuus vuonna 1952 on tosin hiukan pienempi kuin edellisenä vuotena ja suunnilleen sama kuin viimeisenä puolivuotiskautena ennen aborttilain voimaanastumista. Näin lyhyen observatioajan puitteissa sekä suhteellisen pienen materiaalin perusteella on kuitenkin mahdotonta sanoa, ovatko vuosittaiset aborttiluvut saavuttaneet maksiminsa (1951) ja ovatko ne nyt vähenemään päin. Ilahduttavana piirteenä voitanee kuitenkin pitää sitä, ettei merkkejä rikollisten aborttien lukumäärän jatkuvasta lisääntymisestä ole havaittavissa.

Vertausaineistoksi helsinkiläisiin kohdistuvalle tutkimukselle olen ottanut vastaavat tiedot Lahden kaupungin naistensairaalasta, jossa käytännöllisesti katsoen hoidetaan kaikki lahtelaisten synnytykset sekä abortit (taulukko 2). Tässä vertailuaineistossa kiinnittää huomiota se, että siinä esiintyy myöskin vuoden 1951 kohdalla korkein aborttiprosentti. Tämä tukee mielestäni sitä otaksumaa, että rikollisten raskaudenkeskeytysten kohdalla on huippu jo saavutettu ja ne ovat nyt vähitellen vähenemässä.

Huomiota kiinnittää molemmissa aineistoissa se, että kohdunulkoisia raskauksia ja rypäleraskauksia osoittavat suhdeluvut ovat pysyneet vuosittain vakiona. Tämän perusteella voidaan olettaa, että spontaaniaborttien lukumäärä vuosittain on myöskin pysynyt vakiona, koska se, kuten yllämainitut patologiset tilatkin, on biologisesti määrätty. Aineistoissa esiintyvät vaihtelut aborttien vuosittaisissa määrissä johtunevat siis kriminelleistä aborteista.

Tämänlaatuiseen tutkimukseen sisältyy monia eri virhemahdollisuuksia, jotka vaikeuttavat johtopäätösten tekemistä. Huo- 
mattavimman näistä virheistä muodostavat ne abortit, jotka eivät missään vaiheessa vaadi sairaalahoitoa ja jäävät näinollen kaikkien statistiikkojen ulkopuolelle. Wetterdahl ja Uppmark Ruotsissa ovat arvioineet näiden aborttien osuudeksi $10 \%$ kaikista rikollisesti aiheutetuista keskenmenoista. On lisäksi ajateltavissa, että nykyisenä antibiotikoiden aikakautena ja puoskarien »ammattitaidon» parantuessa tähän ryhmään kuuluvien aborttien lukumäärä kasvaa.

J o h t o päätökset.

Suomen aborttilaki, jota säädettäessä raskaudenkeskeytysindikaatioita lisättiin ja laajennettiin, on odotuksien mukaisesti aiheuttanut laillisten raskaudenkeskeytysten huomattavan lisääntymisen. Tähän on epäilemättä vaikuttanut lisäksi se, että abortti-indikaatioista julkisuuden paistoilla viimevuosien aikana käyty vilkas mielipiteiden vaihto on sekä yleisön että lääkärien keskuudessa aiheuttanut määrätynlaisen »aborttimentaliteetin» syntymisen. Tämän vaikutuksesta mahdollisesti monet, jotka aikaisemmin olisivat nurkumatta vieneet raskautensa luonnolliseen päätökseen, nyi turvautuvat saatavilla olevaan, lailliseen aborttiin. Lääkärien keskuudessa taas ei keskeytysindikaatioiden arvosteleminen ole vielä ehtinyt tänä lyhyenä aikana kiteytyä yhdenmukaiseksi eikä tarpeeksi ankaraksi.

Rikollisten raskaudenkeskeytysten määrään ei aborttilailla ole ensimmäisinä vuosina ollut huomattavasti pienentävää vaikutusta. Synnytykseen päättyvien raskauksien suhteellinen määrä on vuosittain Helsingissä jatkuvasti laskenut. Suurimpana tekijänä tähän vähenemiseen ovat olleet jatkuvasti lisääntyvät lailliset keskeytykset, mutta myöskin aborttien suhteellinen osuus raskauksista on vuoteen 1951 asti jatkuvasti kohonnut. Vuonna 1952 on sekä Helsingin että Lahden aineistossa tapahtunut aborttien suhteellisen osuuden vähenemistä.

On todennäköistä, ettei aborttilain soveltaminen sinänsä — olivat sen sallimat indikaatiot ankarat tai väljät - pysty ratkaisemaan rikollisten raskaudenkeskeytysten yhteiskunnallista ongelmaa. Rikollisiin raskaudenkeskeytyksiin ehkäisevässä mielessä 
kohdistuva valistustoiminta, yhdessä aborttia toivovaan äitiin kohdistuvan tuki- ja huoltotoiminnan kanssa on epäilemättä tehokkain abortin torjuntakeino nykyisessä yhteiskunnassa. Tämän, ehkäisevän abortintorjuntatyön kehittämiseen olisi valtovallan taholta kiinnitettävä erityistä huomiota seuraavien vuosien aikana, jolloin lääkärikunnan taholta tullaan, saatujen kokemuk. sien perusteella tarkistamaan ja tiukentamaan laillisen raskaudenkeskeytyksen indikaatioita.

\section{Kirjallisuutta.}

Apajalahti, A.: Duodecim 55: 263, 1939.

Ingelman-Sundberg, A.: Svenska Läkartidningen 48: 1017, 1951.

Pitkänen, H.: Duodecim 63: 253, 1947.

Turunen, A.: Suom. Lääk.lehti 1942: 214.

Inghe, G.: Sociala Meddelanden 11: 1953.

Abortfrägan: Statens offentliga utredningar 1953: 29. 